\title{
In Vivo Regulation of MAP Kinases in Ratus norvegicus Renal Papilla by Water Loading and Restriction
}

Paul A. Wojtaszek, Lynn E. Heasley, and Tomas Berl

Department of Medicine, University of Colorado School of Medicine, Denver, Colorado 80262

\begin{abstract}
In cultured renal cells, hypertonicity activates multiple mitogen-activated protein kinases (MAPKs) and enhances the expression of heat shock proteins (HSPs). In rats, $24 \mathrm{~h}$ water restriction increased mean urinary osmolality $\left(U_{\text {osm }}\right)$ from $2,179 \pm 153 \mathrm{mOsm} / \mathrm{kg}$ to $2,944 \pm 294 \mathrm{mOsm} / \mathrm{kg}(P<0.001)$ and was associated with significant $(P<0.05)$ increases in the papillary activity of c-Jun $\mathrm{NH}_{2}$-terminal protein kinase (JNK) by $22 \%$, extracellular signal-regulated protein kinase (ERK) by $49 \%$, and p38 MAPK by $15 \%$. Conversely, $24 \mathrm{~h}$ of water-loading ( $U_{\text {osm }} 473 \pm 33 \mathrm{mOsm} / \mathrm{kg}$ ) caused suppression of JNK activity by $43 \%(P<0.001)$, ERK by $39 \%(P<$ $0.05)$, and p38 MAPK by $26 \%(P<0.05)$. No such modulation was observed in the isotonic cortex. c-Jun phosphorylation was decreased in papilla from water-loaded rats by 45\% versus controls. Expression of Hsp 110, inducible Hsp 70 , and Hsp 25 was greater in the hyperosmotic papilla than the isosmotic cortex but was not affected by the animal's hydration state. In cultured inner medullary collecting duct cells, HSP expression was maximal at $500 \mathrm{mOsm} / \mathrm{kg}$, while activation of JNK continued to increase. We conclude that under basal conditions of hydration, these HSPs are maximally expressed in the hypertonic inner medulla, while the activation of all three members of the MAPK family approaches but is not maximal. (J. Clin. Invest. 1998. 102: 1874-1881.) Key words: heat shock proteins • urine • kidney medulla $\bullet$ kidney cortex $\bullet$ hypertonic solutions
\end{abstract}

\section{Introduction}

The cells of the mammalian renal inner medulla are exposed to wide fluctuations in extracellular tonicity between states of diuresis and antidiuresis in the process of urinary concentration and dilution. Under the influence of vasopressin, the osmolality of urine may reach $1200 \mathrm{mOsm} / \mathrm{kg}$ in humans and $3,000 \mathrm{mOsm} / \mathrm{kg}$ in laboratory rats (1). Mechanisms by which cells adapt to such potentially injurious levels of extracellular osmolality include increasing intracellular concentrations of "nonperturbing" osmolytes, either by sodium-coupled uptake

Address correspondence to Dr. Tomas Berl, Box C-281, University of Colorado School of Medicine, 4200 East 9th Avenue, Denver, CO 80262. Phone: 303-315-7204; FAX: 303-315-4852; E-mail: Tomas. Berl@UCHSC.edu

Received for publication 23 June 1998 and accepted in revised form 24 September 1998.

J. Clin. Invest.

(C) The American Society for Clinical Investigation, Inc. 0021-9738/98/11/1874/08 \$2.00

Volume 102, Number 10, November 1998, 1874-1881

http://www.jci.org of organic osmolytes such as inositol or betaine (2), or by the generation of sorbitol through the action of aldose reductase on glucose (3). Both of these functions are regulated at the level of transcription and are under the control of the osmotic response element $(\mathrm{ORE})^{1}$ (4). Additionally, exposure of cultured kidney cells to hyperosmotic conditions increases expression of heat shock proteins (HSPs) (5-7) such as Hsp70, $\alpha \beta$-crystallin, and the recently described Osp94, which has an expression pattern in kidney tissue that parallels the increasing osmotic gradient from the cortex to the inner medulla (8).

The mitogen-activated protein kinase (MAPK) family includes the c-Jun $\mathrm{NH}_{2}$-terminal protein kinases (JNKs), extracellular signal-regulated kinases (ERKs), and p38 MAPKs, where the latter constitute the mammalian counterpart of the osmoregulated HOG-1 in yeast (9). MAPKs have been shown to phosphorylate and activate transcription factors directly, thus regulating gene expression in response to stimuli which activate them (10). All three are activated by hypertonicity in the cultured mouse inner medullary collecting duct cell line, mIMCD-3 (11), as well as in other cultured renal cells $(12,13)$. There is accumulating evidence that transcriptional upregulation of organic osmolyte transporter genes and HSPs in response to hypertonicity is mediated by activation of MAPK family enzymes (14-16).

Additionally, inhibition of JNK2 activity by expression of a dominant negative mutant sensitizes mIMCD-3 cells to killing by exposure to hypertonic medium (17). We therefore hypothesized that since these pathways appear to be vital for cell survival in hypertonic conditions, they would show osmotically regulated activation in the rat renal papilla. The present experiments were thus performed to extend in vitro cultured cell observations on regulation of MAPK by hypertonicity into the in vivo setting. Furthermore, since we have evidence linking the activation of JNKs to HSP70 induction (15), we examined HSP expression under various hydration conditions. Our studies in the rat demonstrate that the activity of all three branches of the MAPK family in the renal papilla is modulated by the animal's hydration state, while papillary expression of several HSPs is already maximal even under water-loaded conditions.

\section{Methods}

Hydration state in rats. Male Sprague-Dawley rats between 200 and $250 \mathrm{~g}$ were housed in metabolic cages with food and water ad libitum for $24 \mathrm{~h}$ prior to the start of the experiment. At that point, water was removed from the "water-restricted" group, and 5\% dextrose was substituted for water in the " $5 \%$ dextrose solution" (D5W) group. All

1. Abbreviations used in this paper: D5W, 5\% dextrose solution; ERK, extracellular signal-regulated protein kinase; HSP, heat shock protein; IMCD, inner medullary collecting duct; JNK, c-Jun $\mathrm{NH}_{2}-$ terminal protein kinase; MAPK, mitogen-activated protein kinase; ORE, osmotic response element. 
animals were given food ad libitum. Animals were treated in this manner for $24 \mathrm{~h}$, after which urine was collected for $1 \mathrm{~h}$ prior to sacrifice. Urine osmolality was measured using a model 3MO MicroOsmometer (Advanced Instruments, Norwood, MA). Rats were euthanized by intraperitoneal injection with pentobarbital, and the kidneys were removed and dissected in ice-cold saline.

Cell culture. The established mIMCD-3 cell line is an SV40 immortalized line provided by S.R. Gullans (Boston, MA) (18). The cells were routinely propagated in a 1:1 mixture of DME and Ham's F-12 nutrient mixture, supplemented with $10 \%$ FBS, $100 \mathrm{U} / \mathrm{ml}$ penicillin, and $100 \mathrm{mg} / \mathrm{ml}$ streptomycin.

Measurement of kinase activity. MAPK activity measurements were carried out as previously $(11,17)$ with minor modifications. Papillary and cortical tissue samples were dissected from the entire kidney and immediately homogenized in ice-cold lysis buffer $(50 \mathrm{mM}$ $\beta$-glycerophosphate, $\mathrm{pH} 7.2,0.5 \%$ Triton $\mathrm{X}-100,0.1 \mathrm{mM}$ sodium vanadate, $2 \mathrm{mM} \mathrm{MgCl}$, $1 \mathrm{mM}$ EGTA, $1 \mathrm{mM}$ DTT, $2 \mu \mathrm{g} / \mathrm{ml}$ leupeptin, $4 \mu \mathrm{g} / \mathrm{ml}$ aprotinin). The lysate was centrifuged at $4^{\circ} \mathrm{C}$ for $10 \mathrm{~min}$ $(10,000 \mathrm{~g})$, and the supernatants were adjusted to $100-200 \mu \mathrm{g}$ of protein in $0.5 \mathrm{ml}$. Cultured mIMCD-3 cells were similarly lysed after washing three times in ice-cold Tris-buffered saline.

For measurement of JNK activity, $100 \mu \mathrm{l}$ of $10 \%$ GST-c-Jun agarose beads was added. After $2 \mathrm{~h}$ of rocking incubation at $4^{\circ} \mathrm{C}$, the adsorbed proteins were washed three times in lysis buffer and resuspended in $40 \mu \mathrm{l}$ of $50 \mathrm{mM} \beta$-glycerophosphate $(\mathrm{pH} 7.2), 0.1 \mathrm{mM}$ sodium vanadate, $10 \mathrm{mM} \mathrm{MgCl} 2$, and $100 \mu \mathrm{M}\left[\gamma^{-32} \mathrm{P}\right] \mathrm{ATP}(5,000 \mathrm{cpm} /$ $\mathrm{pmol})$. The reactions were incubated for $20 \mathrm{~min}$ at $30^{\circ} \mathrm{C}$, then stopped by the addition of hot SDS sample buffer, and the lysates were heated in a boiling water bath for $5 \mathrm{~min}$ and subsequently subjected to SDSPAGE on a $10 \%$ polyacrylamide gel, followed by autoradiography. The bands corresponding to phosphorylated c-Jun were excised and counted in a liquid scintillation counter.

For measurement of ERK activity, $2.5 \mu \mathrm{l}$ each of antiserum against ERK1 and ERK2 (\#Sc-94 and \#Sc-93 rabbit polyclonal antisera; Santa Cruz Biotechnology, Inc., Santa Cruz, CA) was added, along with $100 \mu \mathrm{l}$ of $10 \%$ protein A-Sepharose (Pharmacia, Piscataway, $\mathrm{NJ})$. After $2 \mathrm{~h}$ of rocking incubation at $4^{\circ} \mathrm{C}$, the adsorbed proteins were washed three times in lysis buffer and resuspended in $40 \mu \mathrm{l}$ of $50 \mathrm{mM} \beta$-glycerophosphate ( $\mathrm{pH} 7.2$ ), $0.1 \mathrm{mM}$ sodium vanadate, 10 $\mathrm{mM} \mathrm{MgCl} 2,100 \mu \mathrm{M}\left[\gamma^{-}{ }^{32} \mathrm{P}\right]$ ATP $(5,000 \mathrm{cpm} / \mathrm{pmol}), 50 \mu \mathrm{g} / \mathrm{ml} \mathrm{IP}-20$ (TTYADFIASGRTGRRNAIHD), and $200 \mu \mathrm{M}$ EGFR (662-681) peptide (RRELVEPLTPSGEAPNQALLR). The reactions were incubated for $20 \mathrm{~min}$ at $30^{\circ} \mathrm{C}$, then stopped by the addition of $10 \mu \mathrm{l}$ of $25 \%$ trichloroacetic acid. EGFR peptide phosphorylation was assessed by phosphocellulose filter binding as previously described (19).

Measurement of p38 MAPK activation was carried out both by kinase assay and by immunoblot (as described below). Measurement of p38 MAPK activity by kinase assay was carried out similarly to the ERK assay, except that $5 \mu \mathrm{l}$ of antiserum against p38 MAPK (\#Sc535 rabbit polyclonal antisera; Santa Cruz Biotechnology, Inc.) was added, and the substrate peptide was $100 \mu \mathrm{g} / \mathrm{ml} \mathrm{recombinant} \mathrm{amino-}$ terminal domain of ATF-2 (ATF-2NT) (20). This assay has generally yielded a significantly lower signal than the JNK or ERK assays (11), so the results were confirmed utilizing a separate Western blot technique described below. Both assays yielded similar results, so data were combined and expressed together.

Immunoblotting. Cultured cells or excised tissue was homogenized as above and lysates were heated in a boiling water bath after the addition of SDS sample buffer. Then, $50 \mu \mathrm{g}$ of protein was loaded per lane on either a $10 \%$ or $12.5 \%$ polyacrylamide gel and subjected to SDS-PAGE. Proteins were transferred to either Immobilon or NitroPlus (M.S.I., Westboro, MA), and the blot was blocked with 5\% BSA, Fraction V (Amresco, Solon, $\mathrm{OH}$ ) in Tris-buffered saline, $\mathrm{pH} 8$, plus $0.1 \%$ Tween 80 for $2 \mathrm{~h}$ at room temperature. Antiserum incubation was done at $4^{\circ} \mathrm{C}$ for $16 \mathrm{~h}$ in $5 \% \mathrm{BSA} / \mathrm{Tween} / \mathrm{TBS}$, after which the membrane was washed with Tween/TBS. Secondary antisera conjugated to horseradish peroxidase was incubated with the membrane for $2 \mathrm{~h}$ at room temperature in 5\% BSA/Tween/TBS, followed by washes as above, and incubation with chemiluminescent substrate. Antibodies against HSPs were obtained from StressGen (Victoria, B.C., Canada) and were either mouse mAbs (\#SPA-810 against inducible Hsp70 and \#SPA-807 against Hsp60) or rabbit polyclonal antibodies (\#SPA-801 against Hsp25 and \#SPA-1101 against Hsp110). An antibody specific for the activated (phosphorylated at Thr180 and Tyr182) form of p38 MAPK was obtained from New England Biolabs (Beverly, MA). The intensity of the bands on Western blot films was determined by scanning with a video image scanner and digitizing software.

Statistics. Urine osmolalities and enzyme activities were analyzed by ANOVA and the Tukey-Kramer multiple comparisons test using the InStat software package (GraphPad Software, San Diego, CA). A $P$ value of $<0.05$ was considered significant.

\section{Results}

Effect of varying states of hydration on JNK, ERK, and p38 $M A P K$ activity and expression. To determine whether the hydration state affected the activity of MAPK in the rat kidney, rats were placed in metabolic cages and given water ad libitum (controls), thirsted for $24 \mathrm{~h}$, or were given D5W ad libitum for $24 \mathrm{~h}$. Rats consume D5W at a higher rate than water, resulting in greater water loading and a significantly less concentrated urine. Urine osmolalities from rats in the three treatment groups were $2,944 \pm 294 \mathrm{mOsm} / \mathrm{kg}$ for thirsted rats, $2,179 \pm 153$ $\mathrm{mOsm} / \mathrm{kg}$ for water ad libitum controls, and $473 \pm 33 \mathrm{mOsm} / \mathrm{kg}$ for rats given D5W ad libitum (mean \pm SE, $n=5)$ after $24 \mathrm{~h}$ of treatment (Fig. 1).

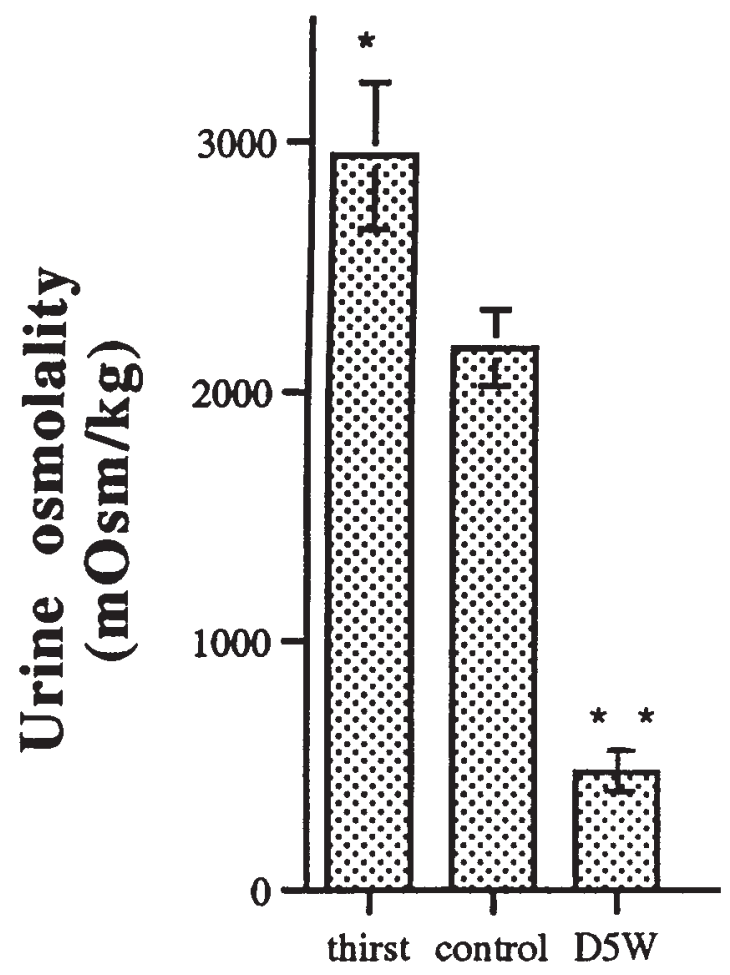

Figure 1. Urine osmolalities from rats either water restricted (thirst), given water ad libitum (control), or water loaded due to consumption of $5 \%$ dextrose $(D 5 W)$. ${ }^{*} P<0.05$ vs. control. ${ }^{*} P P<0.001$ vs. control. $n=5$. 
Fig. $2 A$ shows the activity of JNK in the renal papilla and cortex in various states of hydration. The papillae of thirsted rats had a $22 \%$ increase in JNK activity $(P<0.05, n=5)$ when compared with water ad libitum controls, while the papillae of rats given $\mathrm{D} 5 \mathrm{~W}$ to drink, in which urinary osmolality was decreased by water loading, showed a striking $43 \%$ decrement $(P<0.001, n=5)$. No such changes were observed in the cortex. Immunoblotting utilizing an antiserum that recognizes both the p46 and p54 forms of JNK revealed similar expression levels of p46 JNK in cortex and papilla and slightly higher expression of $\mathrm{p} 54 \mathrm{JNK}$ in the cortex, but no alteration by hydration (Fig. 2 B).

The effects of changes in hydration on ERK activity are shown in Fig. $3 A$. Similar to the case with JNKs, the activity of ERKs increased in the thirsted rat by $49 \%(P<0.05, n=3)$ compared with water ad libitum controls and decreased in the
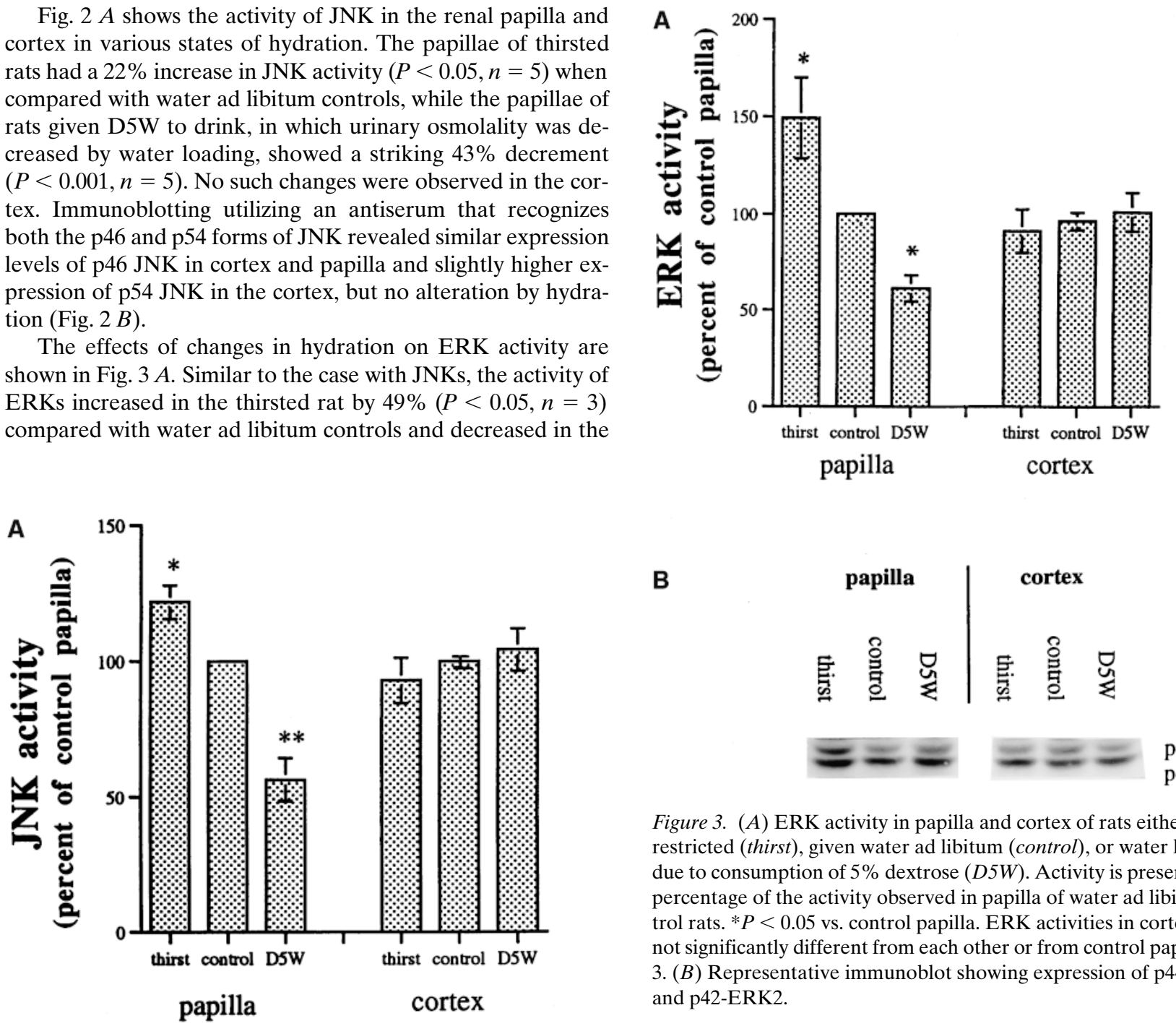

B

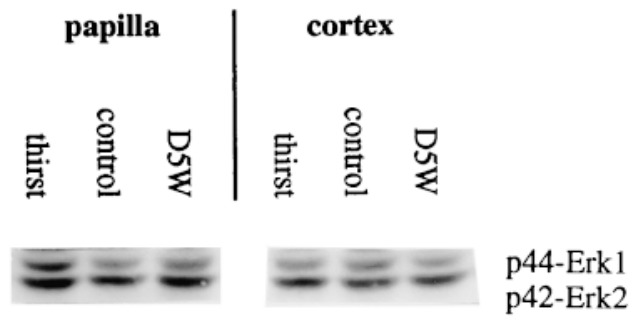

Figure 3. (A) ERK activity in papilla and cortex of rats either water restricted (thirst), given water ad libitum (control), or water loaded due to consumption of $5 \%$ dextrose $(D 5 W)$. Activity is presented as a percentage of the activity observed in papilla of water ad libitum control rats. $* P<0.05$ vs. control papilla. ERK activities in cortex were not significantly different from each other or from control papilla. $n=$ 3. (B) Representative immunoblot showing expression of p44-ERK1 and p42-ERK2.

D5W animals by $39 \%(P<0.05, n=3)$. Immunoblotting using an antiserum that recognizes both p44 and p42 ERK demonstrated that their expression was similar in cortex and medulla and not altered by hydration (Fig. $3 B$ ).

The activation of $\mathrm{p} 38$ MAPK was measured both utilizing a kinase assay and by immunoblotting using an antiserum specific for the activated form of p38 MAPK, which is dually phosphorylated at Thr180 and Thr182. Fig. $4 A$ depicts that, as with JNKs and ERKs, the activity of p38 MAPK is increased in the papillae of thirsted rats by $15 \%(P<0.05, n=3)$ and decreased in rats given D5W by $26 \%(P<0.05, n=3)$. The basal p38 MAPK activity is much lower in the cortex than in the papilla. A minor increase in p38 MAPK activity was observed in the cortex of the water-restricted rats, but due to the much higher p38 MAPK activity in papilla, we cannot rule out that this activity is due to contamination of the cortical tissue by small amounts of papillary tissue. Fig. $4 \mathrm{~B}$ shows a representative immunoblot of activated p38 MAPK reflecting the minor increase in p38 activation in papillae of thirsted rats, the decreased activity in papillae of water-loaded rats, and its absence in the cortex. These changes are not due to differences in the expression of p38 MAPK, as shown by stripping the immunoblot and reprobing with an antiserum that does not distin- 


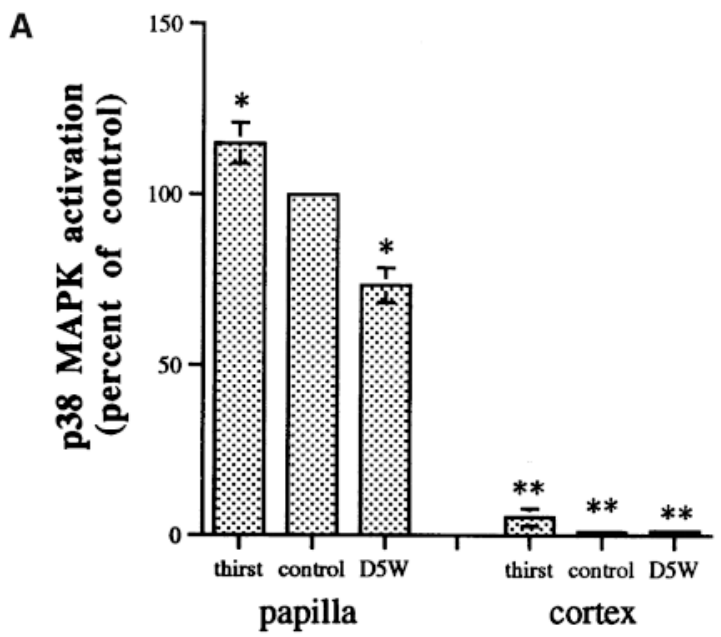

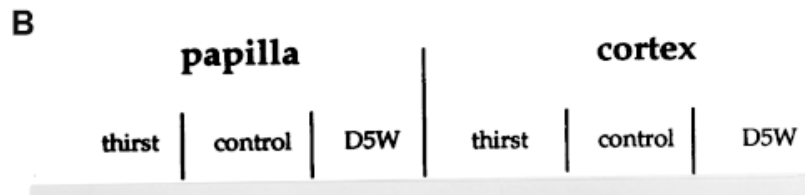

.

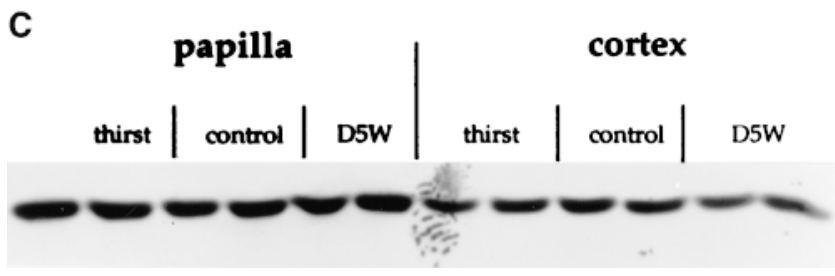

guish between phosphorylated and nonphosphorylated forms (Fig. $4 C$ ).

Effect of varying states of hydration on the phosphorylation of the transcription factor c-Jun in situ. The statistically significant increase in kinase activities among the treatment groups with higher urinary osmolality does not ensure that the magnitude of kinase activation was sufficient to affect intracellular processes downstream of the kinases. To evaluate whether activation of JNK was sufficient to result in increased phosphorylation of endogenous downstream factors in situ, the phosphorylation of endogenous c-Jun in the cells of the papilla was determined by immunoblotting with an antibody specific for the phosphorylated form of the protein. Fig. 5 shows that while the level of c-Jun expression does not vary over the three treatment groups, there is a significant increase in intensity of the phosphorylated band in the papillary cells of the control and water-restricted rats compared with the rats given D5W, which had urinary osmolalities that were much lower than that of the control and water-restricted groups. Densitometric analysis revealed a minimal increase in the thirsted rat $(115 \%$ of control, $n=2)$ but a marked decrement in those given D5W (45\% of control, $n=2)$. This suggests that the magnitude of JNK activation observed in the papillae of rats with more hypertonic urine is physiologically as well as statistically significant. More
Figure 4. p38 MAPK activity in papilla and cortex of rats either water restricted (thirst), given water ad libitum (control), or water loaded due to consumption of $5 \%$ dextrose $(D 5 W)$. $(A)$ Activity is presented as percent of the activity observed in papilla of water ad libitum control rats. $* P<$ 0.05 vs. control papilla. $* * P<0.001$ vs. control papilla. p38 MAPK activities in cortex were not significantly different from each other. $n=3$. (B) Representative Western blot of activated (phosphorylated) p38 MAPK in papilla and cortex of two rats from each treatment group (for details, see Methods). (C) Same representative Western blot shown in $B$ after being stripped and reprobed with antibody against p38 that does not distinguish phosphorylated and nonphosphorylated forms in order to show total expression of $\mathrm{p} 38$ MAPK. importantly, it suggests that the magnitude of JNK activation in control rats given water ad libitum is sufficient to result in near maximal stimulation of downstream transcriptional events.

Effect of varying states of hydration on renal HSP expression. Several groups have documented increased HSP expression in cultured kidney cells in response to hypertonicity (6-8). Expression of Hsp110, inducible Hsp70, and Hsp25 has been shown to follow the corticomedullary osmotic gradient in kidneys of rats given water ad libitum, being highest in the hypertonic inner medulla (21), and has therefore been hypothesized to be osmotically regulated. We have shown that expression of a dominant negative mutant JNK2 cDNA in cultured mouse mIMCD-3 cells blocks hypertonicity-stimulated induction of the inducible Hsp70 (15). We therefore sought to determine whether HSPs are regulated by hydration state in vivo. Fig. 6 shows expression levels of Hsp110, inducible Hsp70, Hsp60, and Hsp25, which were measured by immunoblot in lysates of papillae and cortex of rats that had been either water restricted, given water ad libitum, or D5W ad libitum. The expression levels of Hsp110, inducible Hsp70, and Hsp25 were much higher in the papilla than in the cortex. (Longer exposures of the Hsp100 and Hsp70 blots each show a small amount of expression in the cortex.) However, there was no 


\section{anti-c-Jun antibody}

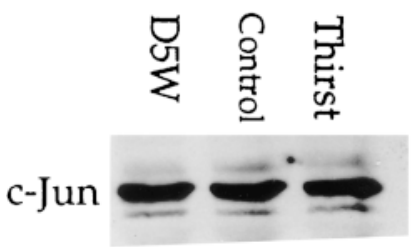

phospho-specific anti-c-Jun antibody

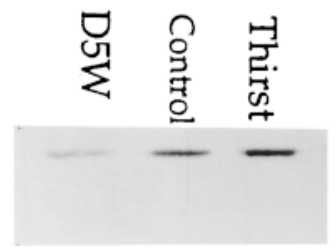

Figure 5. Phosphorylation of transcription factor c-Jun in papilla of rats either water restricted (thirst), given water ad libitum (control), or water loaded due to consumption of $5 \%$ dextrose $(D 5 W)$. Proteins (100 $\mu \mathrm{g}$ ) were subjected to SDS-PAGE and immunoblotted with an antiserum specific for the phosphorylated form of c-Jun (right). The blot was then stripped and reprobed with an antiserum that does not distinguish between phosphorylated and unphosphorylated c-Jun to determine the total level of c-Jun expression (left). Representative data from two experiments.

significant difference in levels of papillary or cortical expression of HSPs among the three treatment groups $(n=4$ for each). Hsp60 was not expressed in papilla, although it was strongly expressed in cortex, suggesting it is not part of a process involved in adaptation to hypertonicity.

Dose response of JNK activation and HSP induction in cultured IMCD cells. We hypothesized that HSP expression in the inner medulla may be osmotically regulated and that, due to the hypertonic environment of the inner medulla, it may be maximally stimulated even under water-loaded conditions. To determine the osmolality at which HSP expression would be expected to be maximal in cells of the renal inner medulla, cultured mIMCD-3 cells were subjected to a range of osmolalities, from 300 to $600 \mathrm{mOsm} / \mathrm{kg}$, by adding $\mathrm{NaCl}$ to the culture

medium. After $24 \mathrm{~h}$ of such treatment, levels of inducible Hsp70 and Hsp110 reached a maximum of expression at 500 $\mathrm{mOsm} / \mathrm{kg}$ (Fig. 7, $B$ and $C$ ). JNK activity levels continued to increase over this range (Fig. $7 A$ ), in agreement with our previous study utilizing mannitol as the osmolyte (11). These results mirror our observation that phosphorylation of c-Jun, the substrate of JNK, shows only a minor increase under conditions of water restriction compared with water ad libitum, while JNK activity continues to increase over this range (Fig. 5).

\section{Discussion}

It is now well established that exposure of cultured renal cells to hypertonicity results in activation of several members of the MAPK pathway (11-13). We have recently expanded these findings to show that expression of a dominant negative JNK2, but not JNK1, sensitizes mIMCD-3 cells to killing by hypertonicity (17). Furthermore, these kinases may play a role in regulation of transcription of osmoregulated genes. In this regard, the observation of Kultz et al. (22), in which a mutant of an upstream kinase of p38 MAPK, MKK3, failed to alter the function of an ORE, stands in contrast with the data of SheikhHamad et al. (14), who reported that the p38 MAPK inhibitor SB203580 blocks hypertonic induction of the betaine transporter mRNA. A role for MAPK is also supported by the observation that mIMCD-3 cells either expressing a JNK2 dominant negative mutant cDNA, or treated with PD098059, a pharmacologic inhibitor of the ERK pathway, or SB203580, an inhibitor of p38 MAPK, display significant inhibition of hypertonic induction of an ORE linked to a reporter construct (16). However, it is of note that aldose reductase message induction was only blocked by a JNK2-dominant negative mutant.

The results of this present study extend observations in cultured renal cells to the in vivo setting. They are the first to

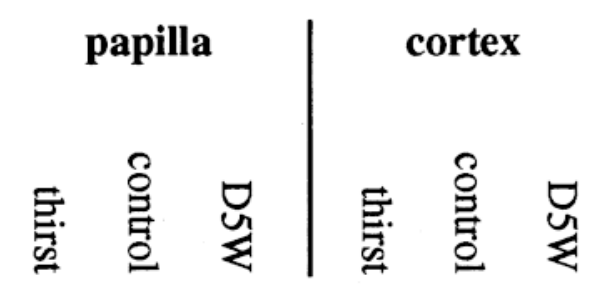

A
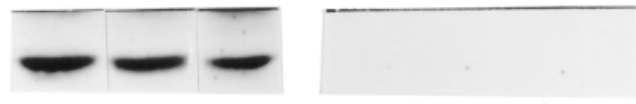

Hsp110

B
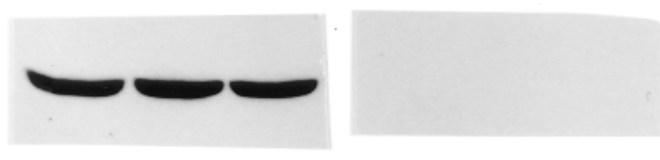

Hsp70 (inducible)

C
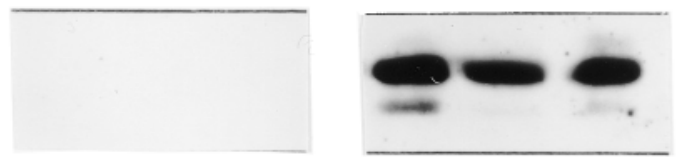

Hsp60

D
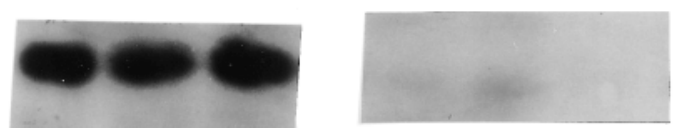

Hsp25
Figure 6. HSP expression in papilla and cortex of rats either water restricted (thirst), given water ad libitum (control), or water loaded due to consumption of $5 \%$ dextrose $(D 5 W) .30 \mu \mathrm{g}$ of protein was subjected to SDS-PAGE, and immunoblotting was carried out as in Methods. Representative data from two or three experiments. 
A

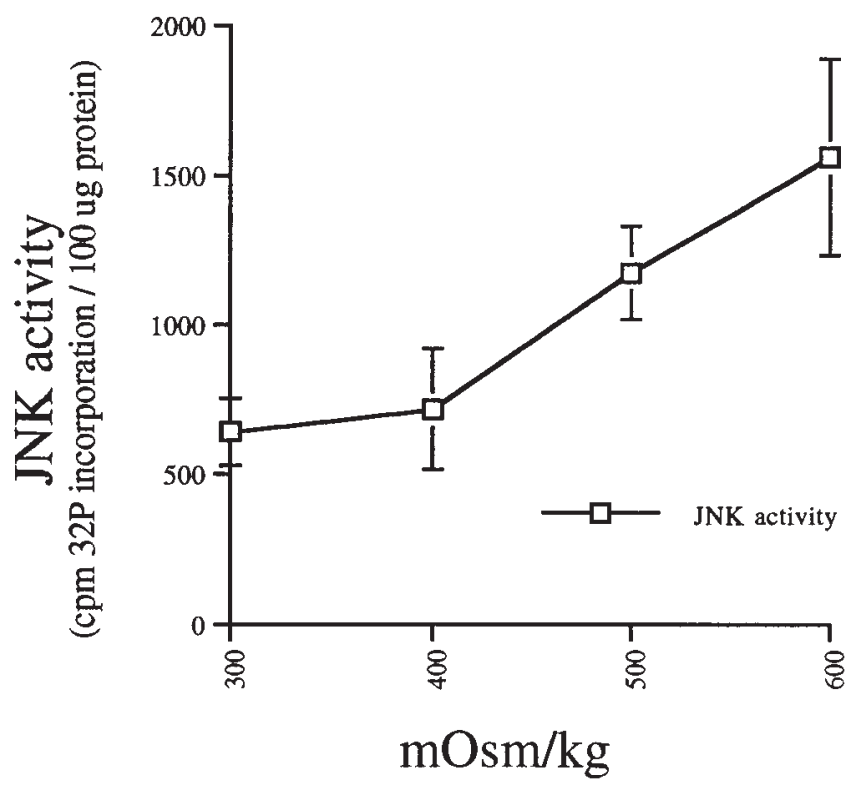

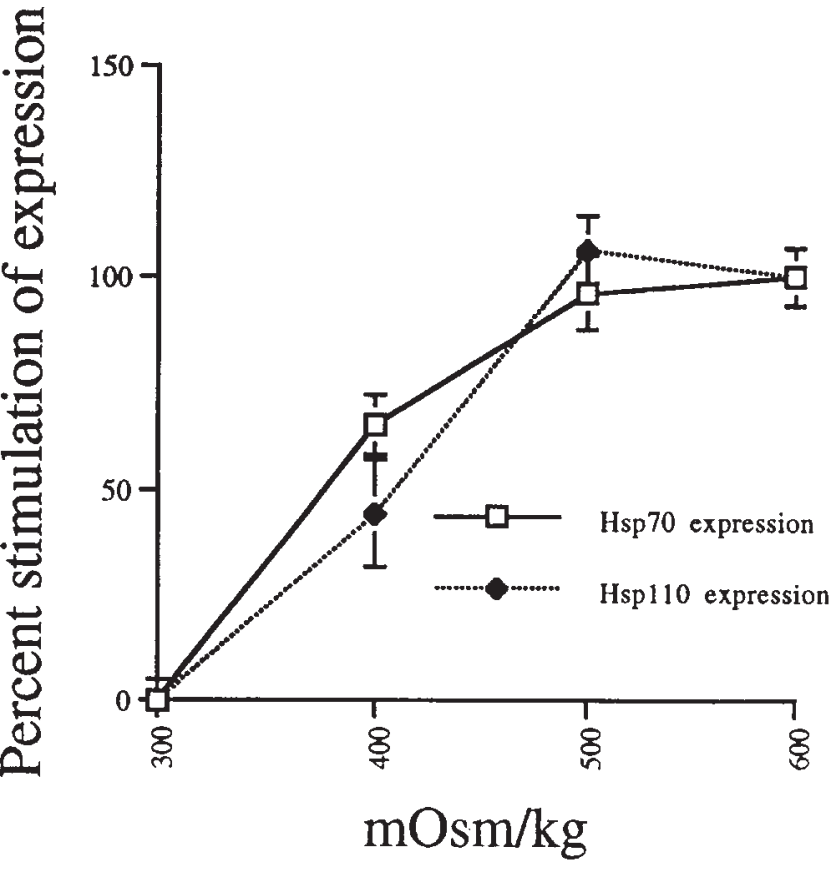

Figure 7. Expression of Hsp110 and inducible Hsp70 in cultured mouse mIMCD-3 cells reaches a maximum under osmotic conditions where JNK activity is still increasing. $(A)$ Graph of dose response of JNK activity after $24 \mathrm{~h}$ of hypertonic treatment. JNK activity was determined as in

Methods. The graph represents a mean of two experiments. (B) Graph of dose response of Hsp110 and inducible Hsp70 expression after $24 \mathrm{~h}$ of hypertonic treatment. Expression of HSPs was quantitated by video scanning of Western blots and expressed as a percentage of the maximal signal. The graph represents a mean of two experiments. $(C)$ Representative Western blot of dose response of inducible Hsp70 and Hsp110 expression in response to $24 \mathrm{~h}$ of hypertonic treatment. demonstrate that in the rat, at the basal level of hydration, which is associated with the excretion of a concentrated urine $(\sim 2,000 \mathrm{mOsm} / \mathrm{kg})$, there is a marked activation of the three members of the MAPK family when compared with rats induced to increase their water intake and thus dilute their urine. A further activation by $\sim 25 \%$ is observed in rats that are water deprived. This modest increase suggests that the fraction of the kinase activity that is osmoregulated is almost maximally stimulated under normal hydration conditions in vivo. In view of the fact that the renal papilla is constantly in a markedly hypertonic environment in order to subserve the needs of the urinary concentrating mechanism, such basal stimulation would appear to be physiologically appropriate. We also demonstrated that these changes in activity of the three MAPK family members observed in the papilla do not occur in the isosmotic cortex and are not due to differential expression of the kinases under various states of hydration.
All three members of the MAPK family have a number of isoforms $(23,24)$, each of which may be regulated differently and perform different functions within the cell. However, since highly specific antisera to the isoforms are not yet available, our experiments cannot discern the particular isoforms which may or may not be activated by hypertonicity in vivo. The existence of isoform specificity is in fact suggested by our previous observation employing stable transfection of cultured cells with epitope-tagged JNK cDNAs, where JNK2, but not JNK1, appears to be osmoregulated (17). Additionally, the kidney has been shown to express mRNAs corresponding to at least three isoforms of p38 MAPK (24). In the present studies, we measured total kinase activity for each MAPK family member, which represents an averaging of the activity of all MAPK isoforms under each condition of hydration. The further dissection of isoforms that are osmoregulated will have to await the development of antibodies capable of specifically immunopre- 
cipitating active MAPK isoforms. Furthermore, the extrapolation of in vitro kinase assays to the in vivo situation must also take into account that levels of regulation in addition to phosphorylation, such as protein-protein interactions and changes in subcellular localization, could occur within the intact cell but cannot be detected with an in vitro assay.

It is worthy of note that we found persistent activation of the MAPK measured as long as $24 \mathrm{~h}$ after the initiation of differential hydration. This is in contrast to the transient nature of MAPK family enzyme activation in experiments involving cultured cells, in which the osmotic stimulus is generally delivered instantaneously by changing the culture medium. While this difference may be due to the more gradual change in tonicity in our in vivo experimental model, it is also possible that other mechanisms of MAPK activation, such as cross talk among other pathways, maintains the duration of the signal in vivo.

We examined whether the phosphorylation of a well known substrate of JNK, the transcription factor c-Jun, is altered in the papilla of the rats in the three treatment groups. We observed a marked enhancement in c-Jun phosphorylation when comparing animals with a high water intake (the D5W group) to those of the basal control group but could detect only a minimal further increase in water-restricted animals. Hence, as with the activities of the MAPKs described above, this observation also reflects the marked stimulation of osmosensing pathways at basal levels of hydration. It is of interest that this pattern mirrors the expression of aldose reductase in Sprague-Dawley rats observed by Cowley et al. (25) in which there was no difference in expression of either aldose reductase mRNA or protein between animals given water ad libitum and animals that were water deprived for $72 \mathrm{~h}$, while aldose reductase mRNA expression was decreased relative to water ad libitum controls only when diuresis was induced by the injection of furosemide.

Several investigators have documented that HSP expression is induced by hypertonicity in cultured renal cells $(7,8,14)$, and the expression of several HSPs has been shown to increase along the corticomedullary osmotic gradient $(21,26)$. We have also found that blocking the JNK pathway inhibits expression of inducible HSP70 mRNA and protein in mIMCD-3 cells (15). We therefore examined the effect of various states of hydration on expression of several HSPs in renal papilla and cortex. In agreement with the observations of Muller et al. (21), we detected more HSP25 in the papilla than in the cortex and more Hsp60 in the cortex than the papilla. We extended these observations since Muller's study did not address the effects of varying hydration. Our data also confirm the observations of Santos et al. (26), who report that in the mouse, Hsp110 is more plentiful in the medulla, and that unlike inducible Hsp70, it is increased by water restriction. We also found that expression of the inducible Hsp70 is not altered by the hydration state, but in the rat, none of the surveyed HSPs, including Hsp110, is altered by this maneuver. Thus, it is important to note that the capacity for increased expression of some HSPs in response to hypertonicity may be greater than others, and that these differences may be species specific. Notably, Kojima et al. identified a mouse cDNA encoding a novel member of the Hsp110/SSE family, Osp94, which shows an increase in renal inner medullary expression in mice after $24 \mathrm{~h}$ of water restriction and also follows the corticomedullary gradient of osmolality in the kidney (8).
It must also be noted that even the animals in the D5W group whose water intake was greatly increased excreted hypertonic urine with $U_{\text {osm }}$ in the $500 \mathrm{mOsm} / \mathrm{kg}$ range. Our data in cultured mIMCD-3 cells examining Hsp70 and Hsp110 expression suggests that this hypertonic stress is sufficient in itself to maximally stimulate the expression of these HSPs. This is in contrast to the activation of the protein kinases, which can be further enhanced, but the activity of which is almost maximally stimulated under basal conditions.

It is attractive to postulate that activation of MAPK activity and induction of HSP expression are coordinated responses that allow renal cells to survive in a hypertonic environment. One would predict that agents that interfere with HSP expression and/or JNK activation could lead to decreased cellular viability by either necrotic or apoptotic mechanisms and thus impair urinary concentration. For example, a number of analgesics and nonsteroidal anti-inflammatory agents have been described as causing papillary necrosis (27). While the mechanism has been postulated to be related to alterations in renal medullary blood flow, this effect has not been fully characterized. Schwenger et al. (28) have demonstrated that sodium salicylate blocks activation of JNK activity by tumor necrosis factor, and we have observed that indomethacin blocks activation of JNK activity in response to hypertonicity (Wojtaszek, P.A., L.E. Heasley, and T. Berl, unpublished observations). An examination of the effects of similar agents on in vivo MAPK activation in the kidney would clearly be of interest.

In conclusion, we have shown for the first time that activity of the MAPK enzymes is not only osmotically regulated in cultured renal cells but also in rat renal papilla in vivo, and that this activation correlates with urinary osmolality. Furthermore, we have shown that mechanisms such as HSP expression and phosphorylation of a downstream transcription factor that presumably protect renal cells from the effects of hypertonicity are maximally or near maximally stimulated under normal conditions of hydration in the hypertonic renal inner medulla.

\section{Acknowledgments}

We are grateful to Kathryn Stack for helpful suggestions and to Timothy Pattison for assistance with quantitation of Western blot data by video image analysis. We thank Steve Gullans for sharing data in advance of publication.

This work was supported by National Institutes of Health grants DK-19928 and GM-48826.

\section{References}

1. Berl, T., and R.W. Schrier. 1997. Disorders of water metabolism. In Renal and Electrolyte Disorders, 5th Edition. Lippincott Dower, Philadelphia. 1-71.

2. Handler, J.S., and M.H. Kwon. 1993. Regulation of renal cell organic osmolyte transport by tonicity. Am. J. Physiol. 265:C1449-C1455.

3. Smardo, F.L., Jr., M.B. Burg, and A. Garcia-Perez. 1992. Kidney aldose reductase gene transcription is osmotically regulated. Am. J. Physiol. 262:C776C782.

4. Ferraris, J.D., C.K. Williams, K.Y. Jung, J.J. Bedford, M.B. Burg, and A. Garcia-Perez. 1996. ORE, a eukaryotic minimal essential response element. J. Biol. Chem. 271:18318-18321.

5. Cohen, D.M., J.C. Wasserman, and S.R. Gullans. 1991. Immediate early gene and HSP70 expression in hyperosmotic stress in MDCK cells. Am. J. Physiol. 261:C594-C601.

6. Sheikh-Hamad, D., A. Garcia-Perez, J.D. Ferraris, E.M. Peters, and M.B. Berg. 1994. Induction of gene expression by heat shock versus osmotic stress. Am. J. Physiol. 267:F28-F34.

7. Rauchman, M.I., J. Pullman, and S.R. Gullans. 1997. Induction of molecular chaperones by hyperosmotic stress in mouse inner medullary collecting duct cells. Am. J. Physiol. 273:F9-F17. 
8. Kojima, R., J. Randall, B.M. Brenner, and S.R. Gullans. 1996. Osmotic stress protein 94 (Osp94). J. Biol. Chem. 271:12327-12332.

9. Brewster, J.L., T. de Valoir, N.D. Dwyer, E. Winter, and M.C. Gustin. 1993. An osmosensing signal transduction pathway in yeast. Science. 259:17601763.

10. Gupta, S., D. Campbell, B. Derijard, and R.J. Davis. 1995. Transcription factor ATF2 regulation by the JNK signal transduction pathway. Science. 267: 389-393.

11. Berl, T., G. Siriwardana, L. Ao, L.M. Butterfield, and L.E. Heasley. 1997. Multiple mitogen-activated protein kinases are regulated by hyperosmolality in inner medullary collecting duct cells. Am. J. Physiol. 272:F304-F311.

12. Itoh, T., A. Yamauchi, A. Miyai, K. Yokoyama, T. Kamada, N. Ueda, and Y. Fujiwara. 1994. Mitogen-activated protein kinase and its activator are regulated by hypertonic stress in Madin-Darby canine kidney cells. J. Clin. Invest. 93:2387-2392.

13. Terada, Y., T. Kimio, M.K. Homma, H. Nonoguchi, T. Tang, T. Yamada, Y. Yuasa, E.G. Krebs, S. Sasaki, and F. Marumo. 1994. Sequential activation of Raf-1 kinase, mitogen-activated protein kinase kinase, MAP kinase, and S6 kinase by hyperosmolality in renal cells. J. Biol. Chem. 272:31296-31301.

14. Sheikh-Hamad, D., J. Di Mari, W.N. Suki, R. Safirstein, B.A. Watts, and D. Rouse. 1998. p38 kinase activity is essential for osmotic induction of mRNAs for HSP70 and the betaine transporter in MDCK cells. J. Biol. Chem. 273:18321837.

15. Wojtaszek, P.A., B. Santos, L.E. Heasley, S.R. Gullans, and T. Berl. 1998. Expression of dominant negative $\mathrm{NH}_{2}$-terminal c-Jun protein kinase 2 inhibits induction of HSP70 by hypertonicity but not by heat in mIMCD-3 cells. $J$. Am. Soc. Nephrol. 9:59A.

16. Chevaile, A., B.C. Santos, R. Stears, R. Kojima, P.A. Wojtaszek, T. Berl, and S.R. Gullans. 1998. Multiple signaling pathways modulate activity of the osmotic response element. J. Am. Soc. Nephrol. 9:51A.

17. Wojtaszek, P.A., L.E. Heasley, G. Siriwardana, and T. Berl. 1998. Dominant negative cJun $\mathrm{N}$-terminal kinase 2 sensitizes renal inner medullary collecting duct cells to hypertonicity-induced lethality independent of organic osmolyte transport. J. Biol. Chem. 273:800-804.

18. Rauchman, M.I., S.K. Nigam, E. Delpine, and S.R. Gullans. 1993. An osmotically tolerant inner medullary collecting duct cell line from an SV-40 transgenic mouse. Am. J. Physiol. 265:F416-F424.
19. Heasley, L.E., S.I. Senkfor, S. Winitz, A. Strasheim, I. Teitelbaum, and T. Berl. 1994. Hormonal regulation of MAP kinase in cultured rat inner medullary collecting tubule cells. Am. J. Physiol. 267:F366-F373.

20. Abdel-Hafiz, H., L.E. Heasley, J.M. Kyriakis, J. Avruch, D.J. Kroll, G.L. Johnson, and J.P. Hoeffler. 1992. Activating transcription factor-2 DNA binding activity is stimulated by phosphorylation catalyzed by $\mathrm{p} 42$ and p54 microtubule-associated protein kinases. Mol. Endocrinol. 6:2079-2089.

21. Muller, E., W. Neuhoffer, A. Ohno, S. Rucker, K. Thurau, and F.X Beck. 1996. Heat shock proteins HSP25, HSP60, HSP72, and HSP73 in isoosmotic cortex and hyperosmotic medulla of rat kidney. Pflugers Arch. 431:608617.

22. Kultz, D., A. Garcia-Perez, J.D. Ferarris, and M.B. Burg. 1997. Distinct regulation of osmoprotective genes in yeast and mammals. J. Biol. Chem. 272: $13165-13170$.

23. Gupta, S., T. Barrett, A.J. Whitmarsh, J. Cavanaugh, H.K. Sluss, B. Derijard, and R.J. Davis. 1996. Selective interaction of JNK protein kianse isoforms with transcription factors. EMBO (Eur. Mol. Biol. Organ.) J. 15:27602770 .

24. Jiang, Y., C. Chen, Z. Li, W. Guo, J.A. Gegner, S. Lin, and J. Han. 1996. Characterization of the structure and function of a new mitogen-activated protein kinase (p38ß). J. Biol. Chem. 271:17920-17926.

25. Cowley, J., J.D. Ferraris, D. Carper, and M.B. Burg. 1990. In vivo osmoregulation of aldose reductase mRNA, protein, and sorbitol in renal medulla. Am. J. Physiol. 258:F154-F161.

26. Santos, B.C., A. Chevaile, R. Kojima, and S.R. Gullans. 1998. Characterization of the Hsp110/SSE gene family response to hyperosmolality and other stresses. Am. J. Physiol. 274:F1054-F1061.

27. Segasothy, M., S. Samad, A. Zulfigar, and W. Bennett. 1994. Chronic renal disease and papillary necrosis associated with the long term use of nonsteroidal anti-inflammatory drugs as the sole or predominant analgesic. Am. J. Kidney. Dis. 24:17-24.

28. Schwenger, P., P. Bellosta, I. Vietor, C. Basilico, E.Y. Skolnick, and J. Vilcek. 1997. Sodium salicylate induces apoptosis via p38 mitogen-activated protein kinase but inhibits tumor necrosis factor-induced c-Jun N-terminal kinase/stress-activated protein kinase activation. Proc. Natl. Acad. Sci. USA. 94: 2869-2873. 